Published in final edited form as:

J Vasc Surg. 2019 November ; 70(5): 1524-1533.e12. doi:10.1016/j.jvs.2019.01.060.

\title{
Impact of Office Based Laboratories on Physician Practice Patterns and Outcomes after Percutaneous Vascular Interventions for Peripheral Artery Disease
}

\author{
Nathan K Itoga, MD', Laurence C Baker, $\mathrm{PhD}^{2}$, Matthew W Mell, MD MS ${ }^{3}$ \\ ${ }^{1}$ Division of Vascular Surgery, Stanford University, Stanford, CA. \\ 2Department of Health Research and Policy, Stanford University, Stanford, CA. \\ ${ }^{3}$ Division of Vascular Surgery, UC Davis, Sacramento, CA
}

\begin{abstract}
Introduction: Percutaneous vascular interventions (PVI) for peripheral artery disease (PAD) have shifted from hospital-based facilities to office-based laboratories (OBLs). The transition to OBLs is due to a variety of factors such as technology advancement, increased efficiency, and financial incentives. We evaluated the impact of physicians "switching" to OBLs use from hospital-based facilities regarding procedure volume and procedure type, and patient outcomes.

Methods: We identified patients with PVI for lower extremity PAD from 2006-2013 in a 20\% Medicare sample, and identified physicians who transitioned from predominantly hospital-based facilities to OBLs (switch physicians) and compared them to those who did not utilize OBLs (control physicians). The main outcomes investigated were average number of PVI at 30-days and 1 -year and atherectomy usage. Patient outcomes included above ankle amputation, major adverse limb events (MALE), and mortality. We used a difference-in-difference model to control for time effects in a multivariate regression model, reported as an odds ratio (OR) and $95 \%$ confidence interval (95\% CI).
\end{abstract}

Results: The cohort comprised 292 switch physicians who treated 7,134 patients (3,888 prior to OBL use and 3,246 patients after transitioning to OBLs), and 3,715 control physicians treating 54,213 patients (36,327 in the pre-period and 17,886 in the post-period). Both switch and control physicians treated more patients with lower extremity wounds over the time period; however, this increase was greater for control physician $(0.7 \%$ vs. $5.5 \%, \mathrm{P}<.001)$. On average, patients treated by switch physicians had 0.05 (95\% CI 0.03-0.07, P<.001) more PVIs performed within 30-days and 0.12 more PVIs (95\% CI 0.08-0.16, P<.001) performed within 1-year of the initial revascularization procedure after the physician transitioned to an OBL. Similarly, patients treated by switch physicians had 0.02 (95\% CI $0.01-0.03, \mathrm{P}=.002)$ more atherectomy procedures

\footnotetext{
Corresponding Author: Matthew W. Mell, 4860 Y Street, Suite 2100, Sacramento, CA 95817, 916-734-3800, mwmell@ucdavis.edu. Publisher's Disclaimer: This is a PDF file of an unedited manuscript that has been accepted for publication. As a service to our customers we are providing this early version of the manuscript. The manuscript will undergo copyediting, typesetting, and review of the resulting proof before it is published in its final citable form. Please note that during the production process errors may be discovered which could affect the content, and all legal disclaimers that apply to the journal pertain.

Presented at the 2018 Western Vascular Society Annual Meeting
} 
at 30-days and $0.03(95 \% \mathrm{CI}, 0.01-0.05, \mathrm{P}=.008)$ more atherectomy procedures at 1-year. Transitioning to OBLs was also associated with a decreased risk in above ankle amputation at 30-days (OR 0.58, 95\% CI 0.38-0.97, P=.009) and 1-year (OR 0.75, 95\% CI 0.60-0.95, P=0.01). However, no statistical difference was observed for MALE and mortality rates at 30-days and 1-year as patients treated by both switch and control physicians experienced similar decreases.

Conclusions: Transitioning to OBLs was associated higher 30-day and 1-year PVI rates and atherectomy rates. Although transitioning to OBLs was associated with lower rates of above ankle amputations; switch physicians treated a lower number of patients with lower extremity wounds.

\section{Keywords}

Office Based Laboratories; Percutaneous Vascular Interventions; Peripheral Artery Disease

\section{Introduction:}

Percutaneous vascular interventions (PVI) have increased in the recent years as technology to restore blood flow to the lower extremity has become safer and more available. ${ }^{1,2}$ In 2008, the US Centers for Medicare and Medicaid Services (CMS) modified reimbursement rates to encourage procedures to be performed in an outpatient setting to increase access for patients with the goal of reducing costs. ${ }^{3}$ This change in payment structure included the use of office based laboratories (OBLs), and as a result PVIs for peripheral artery disease (PAD) have shifted away from hospital-inpatient settings. In an analysis of a 5\% Medicare dataset from 2006-2011 OBL use increased over the time period from 6.0 interventions per 100,000 Medicare beneficiaries to $37.8 .^{4}$

This shift to the outpatient setting and OBLs may be due the development of safer, lessinvasive technologies, but also may be explained by financial incentives and atherecomty use. Mukherjee et al. examined the use of atherectomy use in OBLs and found a high rate of growth in the Medicare population. ${ }^{5}$ In their analysis of a 100\% sample from 2011-2014, atherectomy use in OBLs grew by $298 \%$ compared to an $11 \%$ decrease in the hospital inpatient setting.

Supporters of OBLs have argued that PVI performed in OBLs are safe, improves access for patient care, and may lead to overall spending decreases as the outpatient facility reimbursement is approximately $33-50 \%$ of hospital reimbursements for the similar procedures (i.e. stent and balloon angioplasty). ${ }^{6-8}$ Critics of OBLs argued that physician ownership has increased volume of higher billing procedures (i.e. atherectomy), which is lacking robust clinical evidence. ${ }^{9,10}$

Although the overall trends in procedure location and procedure type have been evaluated, the changes in physician behavior and patient outcomes related to OBLs use have not been studied. The objective of this study was to evaluate the impact of physicians transitioning to OBLs on practice patterns and PAD related outcomes at the patient level. 


\section{Methods:}

\section{Data Source:}

We used the Medicare dataset to investigate changes in physician behavior regarding OBL usage. A 20\% national sample from 2006-2013 was used to identify physicians performing PVI for PAD from the fee for service carrier files.

\section{Physician Population:}

Eligible physicians performing PVI for PAD were identified according to Current Procedural Terminology (CPT) codes, see Supplemental Table I. Procedures were included if the procedure had an associated International Classification of Diseases (ICD-9) diagnosis code related to PAD, see Supplemental Table II. Physicians were included if they performed $\geq 10$ PVIs for PAD. Physicians were identified by the national provider identification (NPI) number. Procedures prior to 2008 were identified by unique physician identification number (UPIN) and linked to NPI numbers. UPINs that did not uniquely identify a NPI number (i.e. had more than one associated NPI) were not included.

Physicians were split into four groups according to OBL use according to location codes in the claims file: (1) switch physicians, (2) control (non-OBL users) physicians, (3) high users of OBLs, and (4) ambiguous OBL users, see Supplemental Figure 1 for further clarification. Switch physicians were identified as those performing PVI in the hospital setting and then transitioned to predominately office based settings. Control physicians strictly performed PVI in hospital based settings (inpatient or outpatient). High users of OBLs and ambiguous OBL users were excluded from the primary analysis.

\section{Patient Population:}

Patients were evaluated if they had a PVI performed for PAD by evaluating the associated ICD-9 diagnosis code. Patients were included in the analysis if the following inclusion criteria were met: enrollment period of $\geq 1$ year from initial PVI encounter, Part A and Part B coverage, fee-for-service coverage (e.g. no health maintenance organization coverage period), no previous open procedures or thrombectomy prior to initial endovascular procedure as defined in supplemental table III, and no hybrid procedure (concomitant open revascularization procedure) on the same day as the initial PVI.

Patients were linked to a physician by NPI number according to the initial PVI procedure for PAD. Patients were included in the final analysis if the physician linkage led to a physician who performed $\geq 10$ PVI for PAD.

Patient demographics regarding age, gender, and race were collected from the beneficiary file. Co-morbidities were collected from the carrier and medpar files using ICD-9 codes up to the time of first PVI for PAD. A Charlson co-morbidity index was calculated by ICD-9 codes as previous described. ${ }^{11}$ The indication for PVI was evaluated for the presence of a lower extremity wound by ICD-9 codes as the presence of a lower extremity wound demonstrated a greater progression of disease compared to PAD alone. 


\section{Procedure information:}

Procedure Location: The procedure location was identified using the line place code in the carrier file. Procedures were classified as inpatient, outpatient hospital affiliated, OBL, or "other" - not identified as one of the previous three locations.

Procedure Type: The type of PVI was defined as one of three procedures: balloon angioplasty alone, stent with or without balloon angioplasty or atherectomy (with or without balloon and/or stent) and identified by CPT code, see Supplemental Table I. The type of initial PVI (balloon vs. stent. vs. atherectomy) was noted.

Procedural Volume: Patient claims after the initial PVI were investigated by CPT and ICD-9 codes to evaluate if additional PVI were performed. Similar criteria as above, a CPT code for lower extremity PAD and ICD-9 code for PAD, were used to calculate total PVI performed per patient at 30-days and 1-year after initial PVI. The percentage of patients with a secondary PVI at 30-days and 1-year were calculated using a binary variable, yes/no. The average number of atherectomy procedures per patient was tabulated from procedures involving atherectomy with a unique procedure date at 30-days and 1-year from the initial PVI.

\section{Patient outcomes:}

Above ankle amputations/ Major Adverse Limb Events (MALE): CPT codes were used to evaluate 30-day and 1-year above ankle amputation rates after the initial PVI, see Supplemental Table III. CPT codes related to open conversion, thrombectomy, and above ankle amputation was used to define MALE, as defined by previous studies to evaluate success of lower extremity PVI for PAD. ${ }^{12,13}$

Hospitalizations: Using the medpar file, hospital admissions were investigated to evaluate 30-day and 1-year hospitalization rates after initial PVI. Hospital admissions were included if the admission date were within 30-days and 1-year from the initial PVI date.

Death: Using the beneficiary file, patient death dates were collected. The 30-day and 1-year mortality rates were calculated from the initial PVI date.

\section{Statistical Analysis:}

Data collection and patient identification was performed using SAS Enterprise 7.1 (Cary, NC). Statistical analysis was performed using Stata 14 (College Station, TX). Descriptive statistics were used to evaluate physician and patient demographics by OBL use groupings. Odds ratios (OR) are reported with $95 \%$ confidence intervals (95\% CI). Mean and standard deviations are reported as mean $\pm \mathrm{SD}$ unless otherwise noted. P-values $<.05$ were considered significant.

A difference-in-differences regression model was used to compare switch physicians to control physicians. The switch date was defined by the first OBL procedure for switch physicians. Patients receiving the first PVI prior to physician the switch date were included in the "pre-switch" period, and patients who received the first PVI on or after the switch 
date were included in the "post-switch" period. For control physicians, a random number generator was used to assign a switch date according to dates matched to the 292 switch physicians. Similarly, patients were included in the "pre-period" if the first PVI was performed before the control physician's switch date, and patients were included in the "post-period" if the first PVI was performed on or after the switch date.

The difference-in-differences model incorporated an interaction term for switch physician status and switch period and ordinary least squares or logistic regression was used to evaluate the dependent variable of interest. Adjustments were made for patient demographics (age, gender, Charlson co-morbidity index), indication for intervention (with or without wound), and procedure type.

Difference-in-differences graphs were constructed by placing patients in 6-month bins from the matched physician's switch date. The regression model included time values at 6-month bins and included an interaction term with switch physician status. Estimated values of the dependent variable were plotted at 6-month intervals using the predicted mean averages of the independent variables, using the "margins" command in Stata, for switch and control physicians.

A secondary analysis of the above outcomes was performed across switch physicians, control physicians, high OBL users (physicians who performed $>80 \%$ of PVI in OBLs), and ambiguious OBL uses (physicians who use OBLs and do not match switch physicians or high OBL criteria). ANOVA and chi-squared tests were used to compare the three types of OBL use physicians. These results are noted in Supplementary files.

This study was approved by the Stanford IRB (Protocol 42984); patient consent was waived given the retrospective nature of this study. CMS approved the use of the dataset according to the data use agreement 51596.

\section{Results:}

From 2006-2013, a total of 199,547 PVI for PAD were identified. The temporal trends for procedure location and procedure type by year are displayed in Supplemental Figures 2a and $2 \mathrm{~b}$, respectively. The location of atherectomy procedures are displayed in Supplemental Figure 3a with an increase in OBLs usage in 2011. The type of procedure performed at OBLs are noted in Supplemental Figure 3b with an increase in atherectomy beginning in 2011.

A total of 4,693 physicians met inclusion criteria performing $\geq 10$ PVI for PAD. Of these $292(6.2 \%)$ were switch physicians, 3,715 (79.2\%) were control physicians (non-OBLS users), 89 (1.9\%) high OBL users, and 597 (12.7\%) were ambiguous OBL users. The distribution for the first office procedure for switch physicians is shown in Supplemental Figure 4a with a median switch date of Jul 6, 2011. The distribution of the randomly generated matched switch date for control physicians is shown in Supplemental Figure 4b.

Switch physicians treated 7,134 patients (3,888 prior to OBL use and 3,246 patients after transitioning to OBLs), and control physicians treated 54,213 patients $(36,327$ in the pre-

J Vasc Surg. Author manuscript; available in PMC 2021 October 29. 
period and 17,886 in the post-period). Physician demographics for switch and control physicians are noted in Table I with vascular surgeons (35.6\%) and cardiologists (31.2\%) comprising the majority percentage of switch physicians. Switch physicians transitioned from $0 \%$ of PVI performed in OBLs to $70.0 \%$ in the post-switch period. For control physicians PVI increased in hospital outpatient setting from 53.0\% in the pre-period to $62.0 \%$ in the post-period.

For patients treated by switch physicians the average Charlson co-morbidity index was 5.6 \pm 3.2 in the pre-switch period and increased to $6.7 \pm 3.5$ in the post-switch period, $\mathrm{P}<.001$. Similarly, for patients treated by control physicians the Charlson index increased from $5.4 \pm 3.1$ to $6.5 \pm 3.4$ in the post period, $P<.001$. The average increase of 1.1 in the Charlson score across the switch period was similar to the average increase of 1.1 for patients treated by control physicians in the pre- and post-period and was not statistically significant, difference-in-differences $\mathrm{P}=.77$, see Table II. Similarly, co-morbidities did not change significantly across the two periods, except for higher cerebrovascular disease in patients treated by switch physicians and higher increase in diabetes with chronic complications in patients treated by control physicians. Lower extremity wounds were more prevalent in the post-switch and post-period; however, the increase across time periods was greater for patients treated by control physicians $(0.7 \%$ vs. $5.8 \%, \mathrm{P}<.001)$.

\section{Procedural Usage}

30-day PVI rates: Patients treated by switch physicians had an average of $1.10 \pm 0.31$ PVI performed within 30-days of the initial PVI in the pre-switch period, with an increase to $1.16 \pm 0.38 \mathrm{PVI}$ after physicians switched to OBLs in the post-switch period, $\mathrm{P}<.001$, see Table III. Compared to control physicians, the average number of PVI performed within 30-days was similar in the pre-period and post-period ( $1.09 \pm 0.31$ vs. $1.09 \pm 0.31, \mathrm{P}=.99)$. A comparison of the overall trend of average PVI per patient according to physician switch date is shown in Figure 1a with switch physicians performing on average of 0.05 more PVI within 30-days (95\% CI 0.03-0.07, P<.001).

1-year PVI rates: Similarly, the average number of PVI performed by switch physicians within 1-year of initial PVI increased from $1.39 \pm 0.73$ prior to OBL use to $1.49 \pm 0.81$ after transition to OBLs, $\mathrm{P}<.001$. For control physicians the average number of PVI at 1-year was $1.33 \pm 0.67$ in the pre-period and decreased to $1.31 \pm 0.64$ in the post-period, $\mathrm{P}<.001$, see Table III. The average 1-year PVI rates according to switch date is shown in Figure 1b. Multi-variable difference-in-difference analysis showed that physicians switching to OBLs increased 1-year PVI rates by 0.12 procedures per patient (95\% CI, 0.8-0.16, $\mathrm{P}<.001$ ), see Supplemental Table IV. Other co-variates affecting 1-year PVI rates included black race $(0.04,95 \%$ CI $0.02-0.06, \mathrm{P}<.001)$ and Hispanic ethnicity $(0.09,95 \%$ CI $0.04-0.13$, $\mathrm{P}<.001)$ and atherectomy as the first PVI $(0.10,95 \% \mathrm{CI} 0.08-1.12, \mathrm{P}<.001)$. A diagnosis of dementia was associated with a decrease in 1-year PVI by 0.08 (95\% CI $-0.10,-0.06$, $\mathrm{P}<.001)$.

30-day and 1-year repeat procedure rates: Evaluation of percentage of patients with subsequent PVI at 30-days and 1-year by switch date showed similar results with the 
average number of PVI procedures performed, see Figure 1c and 1d respectively. Switching to OBLs increased the risk for a subsequent PVI at 30-days (OR 1.63, 95\% CI 1.39-1.90, $\mathrm{P}<.001)$ and 1-year (OR 1.42, 95\% CI 1.27-1.58, P<.001).

Type of initial procedure: Examination of type of first procedure for PVI showed increases in atherectomy rates for both switch physicians and control physicians. For patients treated by switch physicians atherectomy as the first procedure increased from $23.8 \%$ prior to OBL use to $26.4 \%$ after OBL use, $\mathrm{P}<.001$. For control physicians atherectomy as the first procedure increased from $20.4 \%$ in the pre-period to $26.2 \%$ in the post period, $\mathrm{P}<.001$. Switching to OBL use was associated with a slight decrease in atherectomy use as the first choice of PVI (OR 0.85, 95\% CI 0.75-0.95, P=.005).

Atherectomy volume: The average number of atherectomy procedures performed at 30-days and 1-year according to months from switch date is shown in Figure 2a. \& 2 b. Adjusting for demographics, co-morbidities and first procedure type, the effect of switching to OBLs increased atherectomy rates by 0.02 (95\% CI 0.01-0.03), $\mathrm{P}=.002$ at 30-days and increased atherectomy rates by $0.03,(95 \% \mathrm{CI}, 0.01-0.05, \mathrm{P}=.008)$ at 1 -year.

\section{Patient outcomes}

30-day, 1-year above ankle amputation rates: For patients treated by switch physicians, the 30-day above ankle amputation rate decreased from 2.3 to $1.1 \%$ after transition to OBL use, $\mathrm{P}<.001$. For patients treated by control physicians, the 30-day above ankle amputation rate did not differ significantly between the pre and post-period $2.3 \%$ vs. $2.1 \%, \mathrm{P}=.11$. The 1-year amputation rates also decreased significantly for both control and switch physicians. Switching to OBLs was associated with a decreased risk in above ankle amputation at 30-days (OR 0.58, 95\% CI 0.38-0.97, $\mathrm{P}=.009$ ) and 1-year (OR 0.75, $95 \% \mathrm{CI} 0.60-0.95, \mathrm{P}=0.01)$. Other factors increasing 1-year above ankle amputation risk include: diabetes with complication (OR 1.33, 95\% CI, P<.001), renal disease (OR 1.22, 95\% CI 1.16-1.26, P<.001), Black race (OR 2.28, 95\% CI 2.09-2.49, $\mathrm{P}<.001)$ and Hispanic ethnicity (OR 1.71, 95\% CI 1.43-2.06, P<.001), and lower extremity wound at the first PVI (OR 5.35, 95\% CI 4.88- 5.86, P<.001), see Supplemental Table V.

30-day, 1-year MALE: For patients treated by switch physicians 30-day MALE decreased from $5.7 \%$ prior $\mathrm{OBL}$ use to $5.2 \%$ after $\mathrm{OBL}$ use, $\mathrm{P}=.34$. For patients treated by control physicians, 30-day MALE decreased from 5.7\% in the pre-period to 5.1\% in the post-period, $\mathrm{P}=.006$. The 1-year MALE rates decreased at similar rates for both switch and control physicians, and switching to OBLs was not associated with a significant decrease in 30-day or 1-year MALE by difference-in-difference analysis, $\mathrm{P}=.87, .20$, respectively.

Hospitalization Rates: For patients treated by switch physicians, the 30-day hospitalization rate decreased from $24.3 \%$ to $17.6 \%$ after switching to OBLs, $\mathrm{P}<.001$. For patients treated by control physicians, the 30-day hospitalization rates did not differ significantly between the pre and post-period $23.8 \%$ vs. $23.4 \%, \mathrm{P}=.29$. The 1-year hospitalization rates decreased from $61.3 \%$ to $48.2 \%$ after switching to OBLs, $\mathrm{P}<.001$ and also decreased for control physicians from $59.0 \%$ in the pre-period to $52.2 \%$ in the 
post -period, $\mathrm{P}<.001$. Switching to OBLs was associated with a greater decreased risk in hospitalization rates at 30-days (OR 0.64, 95\% CI 0.57-0.74, P<.001) and 1-year (OR 0.72, 95\% CI $0.65-0.81, \mathrm{P}<.001)$.

Mortality Rates: For patients treated by switch physicians, the 30-day mortality rates decreased from $1.0 \%$ to $0.3 \%$ after switching to OBLs, $\mathrm{P}<.001$. For patients treated by control physicians, the 30-day mortality rates also decreased significantly between the pre and post-period $1.1 \%$ vs. $0.5 \%, \mathrm{P}<.001$. The 1 -year mortality rates decreased also decreased at similar rates for both switch and control physicians. Switching to OBLs was not associated with a decreased risk in 30-day or 1-year mortality rates, $\mathrm{P}=.41, .81$, respectively.

\section{Secondary Analysis}

Secondary analysis included high OBL use physicians ( $\mathrm{n}=89$ ), treating 887 patients, and ambiguous OBL use physicians ( $\mathrm{n}=597$ ), treating 12,643 patients. High OBL users showed a different demographic by physician type with radiologists (33.7\%), cardiologists (29.2\%), and other physicians (21.3\%) comprising the majority of high OBL use physicians, see Supplemental Table VI.

Patients treated by high OBL use physicians had the highest Charlson index score 7.6 \pm 3.7 , compared to switch, control, and ambiguous OBL use physicians, see Supplemental Table VII. High OBL use physicians also treated a higher percentage of Black, Asian, and Hispanic patients. High use OBL physicians also treated the lowest percentage of patients with lower extremity wounds (27.6\%) compared to the other physician groups, $\mathrm{P}<.001$.

Regarding procedural usage and type, the average PVI per patient at 30-days and 1-year was the highest for high OBL physicians with $1.16 \pm 0.39$ procedures performed within 30 days and $1.57 \pm 0.87$ procedures performed within 1-year, see Supplemental Table VIII. Similarly, high OBL use physicians had the highest percentage of patients with repeat PVI within 30-days (14.9\%) and 1-year (40.6\%). Atherectomy was used the least (16.9\%) as the initial PVI type by high OBL physicians and average 30-day and 1-year atherectomy rates per patient were the lowest among the four groups.

Regarding patient outcomes, high OBL use physicians had the lowest MALE rates at 30-day (2.7\%) and 1-year (11.4\%), and lowest above ankle amputation rates at 30-days (0.7\%) and 1-year (4.5\%). Hospitalization rates were also the lowest for high OBL use physicians at 30-days (14.3\%) and 1-year (51.4\%).

\section{Discussion:}

This analysis found an increase in average PVI at 30-days and 1-year (see Figure 1a, 1b) and higher percentages of patients receive secondary PVI procedures (see Figure 1c, 1d) when physicians transition to OBLs. As ownership of OBLs allows physicians to collect of facility fees and increase profits from a higher number of procedures, these financial incentives may influence the increase in PVI rates. Previous studies regarding physician ownership of health care capital have shown similar increases in resource usage. Ownership of outpatient surgical centers was associated with increases in carpal tunnel 
release, cataract excision, colonoscopy, and knee arthroscopy. ${ }^{14}$ Another study demonstrated physician ownership of MRI machines increased the amount of studies performed for lower back pain. ${ }^{15}$ Furthermore, when orthopedic surgeons own a MRI machine the probability of having surgery increase by $34 \%$.

The increase in average PVI at 30-days of 0.05 procedures and average PVI at 1-year of 0.12 procedures for switch physicians may seem low to some readers. This increase in PVI may represent greater access to care, which was the objective of CMS reimbursement modifications to incentivize procedures to increase efficiency. With the current dataset, we are unable to determine if each PVI procedure was done for "appropriate" indications, but emphasize that on average physician practices change when transitioning to OBL use. Whether an increase in PVI improves efficiency and patient satisfaction needs to be investigated further. Furthermore, the appropriateness of procedures by high OBL users need to be investigated further as patients receive on average 0.24 more PVI at 1-year compared to control physicians and $15.7 \%$ more patients receive secondary PVI within 1-year, see Supplemental Table VIII.

Regarding patient outcomes, although transitioning to OBLs was not associated with decreases in 30-day and 1-year mortality rates and MALE, the main benefit associated with physicians transitioning to OBLs was a greater decrease in 30-day and 1-year above ankle amputation rates. However, as lower extremity wound status ( $\mathrm{OR}=5.35$, see Supplemental Table V) was the highest predictor of above ankle amputation, healthier patient selection by switch physicians (i.e. performing PVI on patients without lower extremity wounds (see Table II, Supplemental Table VII)) may explain the lower rate of above ankle amputations. Although a greater decrease was observed in 1-year above ankle amputation rates for switch physicians, the absolute difference in 1-year amputation rates in the post-switch period and post-control period only differed by $0.4 \%$ ( $4.8 \%$ vs. $5.2 \%$ ). Therefore, if patient outcomes are comparable between hospital and OBL locations, further studies regarding cost need to be evaluated to see if there is a net saving to society with OBL use.

Our study also found that switching to OBLs was not associated with an increase in atherectomy usage as the first PVI compared to control physicians (See Table II, Figures $2 \mathrm{a}$ and $2 \mathrm{~b}$ ). However, the average atherectomy rates at 30-days and 1-year was higher when physicians switch to OBLs by 0.02 and 0.03 procedures respectively. A possible explanation for this is physicians who transition to OBLs may use balloon angioplasty at higher rates for the first procedure, with increased us of atherectomy as a secondary procedure. In our analysis atherectomy as the first procedure was associated with lower 1-year amputation rates compared to balloon angioplasty ( $\mathrm{OR}-0.85,95 \% \mathrm{CI} 0.78-0.93, \mathrm{P}<.001)$, however, stenting as the first procedure was associated with a lower risk (OR $-0.73,95 \% \mathrm{CI} 0.67-$ $0.80, \mathrm{P}<.001)$, see Supplemental Table V.

Our study is consistent with atherectomy rates increasing in OBLs from 2011; however, this increase is presented differently in our study. From 2011 to 2013, total atherectomy procedures increased by $287 \%$ (see Supplemental Figure 3b) similar to the $298 \%$ increase from 2011-2014 reported by Mukherjee et al. ${ }^{16}$ However, our analysis shows that atherectomy is predominately performed in the outpatient hospital and inpatient hospital 
setting, see Supplemental Figure 3a. The overall increase in atherectomy usage began in 2011, when atherectomy procedures increased from 3,376 in 2010 to 6,478 in 2011, see Supplemental Figure 2b. In 2011, CMS revised lower extremity revascularization coding and reimbursement. ${ }^{17}$ In addition to bundling procedures, a higher reimbursement was given to atherectomy to increase the adaptation of newer technology. As a previous study showed a $2 \%$ increase in payment rates lead to a $3 \%$ increase in care provisions ${ }^{18}$, similarly increases in atherectomy reimbursement led to higher use of atherectomy across all physicians settings. Our study found that control physicians increased atherectomy rates as the first PVI by nearly $6 \%$, demonstrating that financial incentives influence procedure choices despite the lack of definitive clinical evidence. ${ }^{9}$ We also note that there may be institutional restrictions on the use of atherectomy at certain hospitals and physicians vary in their uptake and utilization of new technologies.

\section{Limitations}

This study has limitations that warrant further discussion. First, given the retrospective nature of the claims dataset, we are unable to analyze how anatomy and patient presentation affected treatment decision. The clinical severity, duration, and location of a wound as well as patient vasculature amendable to PVI were unable to be evaluated. Second, this study does not capture the full scope of transitioning to OBLs as physician practice may treat non-Medicare insured patients. Similarly, as this dataset contains a $20 \%$ random sample of all Medicare patients, outlier physicians and patients with high numbers of PVIs may not be fully captured. Third, we were unable to ascertain if PVI for PAD increased at the expense of other disease treatments outside of PAD (e.g. venous and/or dialysis intervention) for physicians transitioning to OBLs.

Fourth, given that laterality of procedure was not specifically defined for all PAD procedures, the true "re-intervention" rate is unknown as procedures may have occurred on the contralateral limb. Nonetheless, the increase in subsequent PVI shows that procedure volume increased when transitioning to OBL use. Similarly, MALE and amputation rates are assumed to be on the ipsilateral side as the initial endovascular procedure. Fifth, this analysis does not distinguish between physicians using OBLs and those who own OBLs. For example, one physician can be using a partner's or university owned OBL with financial incentive agreements which were unable to be delineated from the dataset. Sixth, we assigned patients to physicians by the first PVI and note that patients may be treated by multiple physicians with different practice styles. Finally, as the claims dataset does not differentiae by type of atherectomy (orbital vs. directional, vs. laser vs. rotational), drug coated balloon, or by stent design (drug eluting stent vs. non-drug eluting stent vs. covered stent) a comparison of these modalities was not performed and is beyond the scope of this study; however, the initial procedure type (balloon vs. stent vs. atherectomy) was controlled for in our regression model. 


\section{Conclusions:}

The practice of transitioning to OBLs was associated with increases in PVI and atherectomy rates at 30-days and 1-year highlighting the impact of physician ownership of healthcare capital.

\section{Supplementary Material}

Refer to Web version on PubMed Central for supplementary material.

\section{Acknowledgements}

This work was supported by a National Institutes of Health, National Center for Advancing Translational Science, Clinical and Translational Science Award (TL1TR001084).

\section{References}

1. Goodney PP, Beck AW, Nagle J, Welch HG, Zwolak RM. National trends in lower extremity bypass surgery, endovascular interventions, and major amputations. J Vasc Surg 2009;50:54-60. [PubMed: 19481407]

2. Jaff MR, Cahill KE, Yu AP, Birnbaum HG, Engelhart LM. Clinical Outcomes and Medical Care Costs Among Medicare Beneficiaries Receiving Therapy for Peripheral Arterial Disease. Ann Vasc Surg 2010;24:577-87. [PubMed: 20579582]

3. Centers for Medicare \& Medicaid Services (CMS) H. Medicare program; prospective payment system for long-term care hospitals RY 2008: annual payment rate updates, and policy changes; and hospital direct and indirect graduate medical education policy changes. Final rule. Fed Regist 2007;72:26869-7029. [PubMed: 17520779]

4. Jones WS, Mi X, Qualls LG, Vemulapalli S, Peterson ED, Patel MR, et al. Trends in settings for peripheral vascular intervention and the effect of changes in the outpatient prospective payment system. J Am Coll Cardiol 2015;65:920-7. [PubMed: 25744009]

5. Mukherjee D, Hashemi H, Contos B. The disproportionate growth of office-based atherectomy. J. Vasc. Surg, vol. 65, 2017, p. 495-500. [PubMed: 27986487]

6. Jain K, Munn J, Rummel MC, Johnston D, Longton C. Office-based endovascular suite is safe for most procedures. J Vasc Surg 2014;59:186-91. [PubMed: 24210929]

7. Jain KM, Munn J, Rummel M, Vaddineni S, Longton C. Future of vascular surgery is in the office. J Vasc Surg 2010;51:509-14. [PubMed: 20141969]

8. Carr JG. Era of Change in Sites of Service for Peripheral Vascular Intervention Requires New Ways to Look at Costs. J Am Coll Cardiol 2015;66:1741-3. [PubMed: 26449147]

9. Heidenreich P. Incentives for clinical decisions where evidence is lacking. J Am Coll Cardiol 2015;65:928-30. [PubMed: 25744010]

10. Lin PH, Chandra FA, Shapiro FE, Osman BM, Urman RD, Ahn SS. The Need for Accreditation of Office-Based Interventional Vascular Centers. Ann. Vasc. Surg, vol. 38, Elsevier; 2017, p. 332-8. [PubMed: 27554695]

11. Deyo RA, Cherkin DC, Ciol MA. Adapting a clinical comorbidity index for use with ICD-9-CM administrative databases. J Clin Epidemiol 1992;45:613-9. [PubMed: 1607900]

12. Brooke BS, Kraiss LW, Stone DH, Nolan B, De Martino RR, Reiber GE, et al. Improving Outcomes for Diabetic Patients Undergoing Revascularization for Critical Limb Ischemia: Does the Quality of Outpatient Diabetic Care Matter? Ann Vasc Surg 2014;28:1719-28. [PubMed: 24911812]

13. Conte MS, Geraghty PJ, Bradbury AW, Hevelone ND, Lipsitz SR, Moneta GL, et al. Suggested objective performance goals and clinical trial design for evaluating catheter-based treatment of critical limb ischemia. J Vasc Surg 2009;50:1462-1473.e3. [PubMed: 19897335] 
14. Hollingsworth JM, Ye Z, Strope SA, Krein SL, Hollenbeck AT, Hollenbeck BK. Physicianownership of ambulatory surgery centers linked to higher volume of surgeries. Health Aff (Millwood) 2010;29:683-9. [PubMed: 20368599]

15. Shreibati JB, Baker LC. The Relationship between Low Back Magnetic Resonance Imaging, Surgery, and Spending: Impact of Physician Self-Referral Status. Health Serv Res 2011;46:136281. [PubMed: 21517834]

16. Mukherjee D, Hashemi H, Contos B. The disproportionate growth of office-based atherectomy. J. Vasc. Surg, vol. 65, 2017, p. 495-500. [PubMed: 27986487]

17. Centers for Medicare \& Medicaid Services (CMS), HHS. Medicare program; payment policies under the physician fee schedule and other revisions to Part B for CY 2011. Final rule with comment period. Fed Regist 2010;75:73169-860. [PubMed: 21121181]

18. Clemens J, Gottlieb JD. Do Physicians' Financial Incentives Affect Medical Treatment and Patient Health? Am Econ Rev 2014;104:1320-49. [PubMed: 25170174] 


\section{Article Highlights:}

\section{Type of Research:}

Retrospective comparative cohort study of a $20 \%$ Medicare sample

\section{Key findings:}

Physicians who transition to office-based laboratories (OBLs) were found to perform on average 0.05 more percutaneous vascular interventions (PVIs) within 30-days of the initial procedure and 0.12 more PVIs within 1-year. Similarly, transitioning to OBLs was associated with 0.02 more atherectomy procedures at 30-days and 0.03 more atherectomy procedures at 1-year.

\section{Take home message:}

Transitioning to OBLs from hospital based settings was associated higher 30-day and 1-year PVI rates and atherectomy rates.

\section{Table of Contents Summary:}

This retrospective study of Medicare claims database found physicians transitioning to office-based laboratories performed more percutaneous vascular interventions, and atherectomies at 30-days and 1-year for lower extremity peripheral arterial disease. Increases in procedure volume were associated with physician ownership of health care capital. 
A

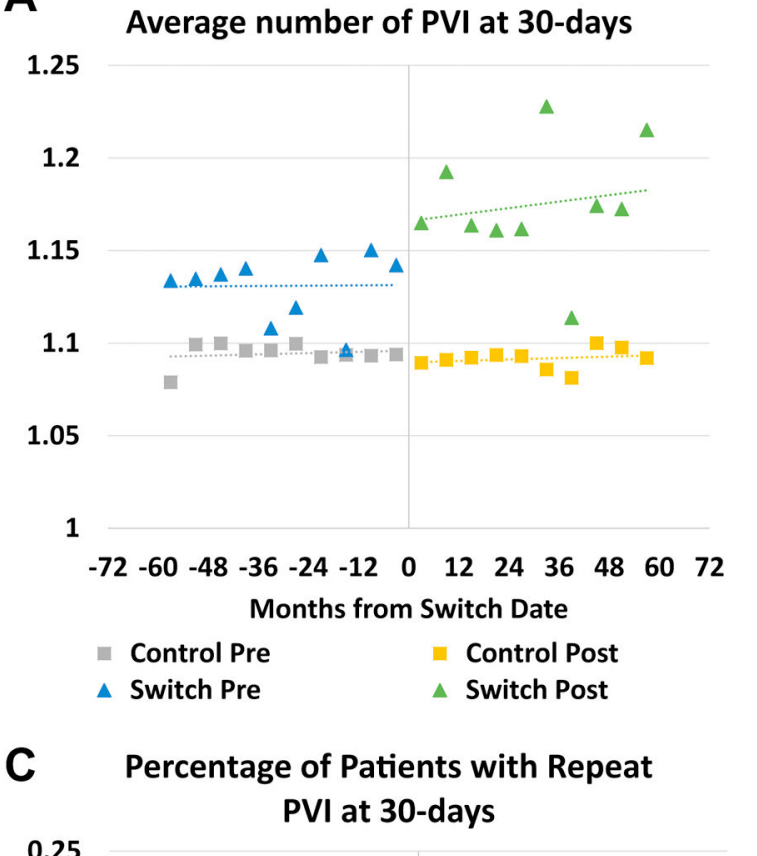

0.25

0.2

0.15

0.1

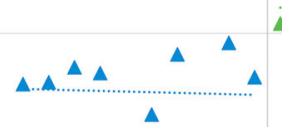

0.05

$\begin{array}{lllllllllllll}-72 & -60 & -48 & -36 & -24 & -12 & 0 & 12 & 24 & 36 & 48 & 60 & 72\end{array}$ Months from Switch Date

- Control Pre

II Control Post

\ Switch Pre

A Switch Post

Figure 1.
B

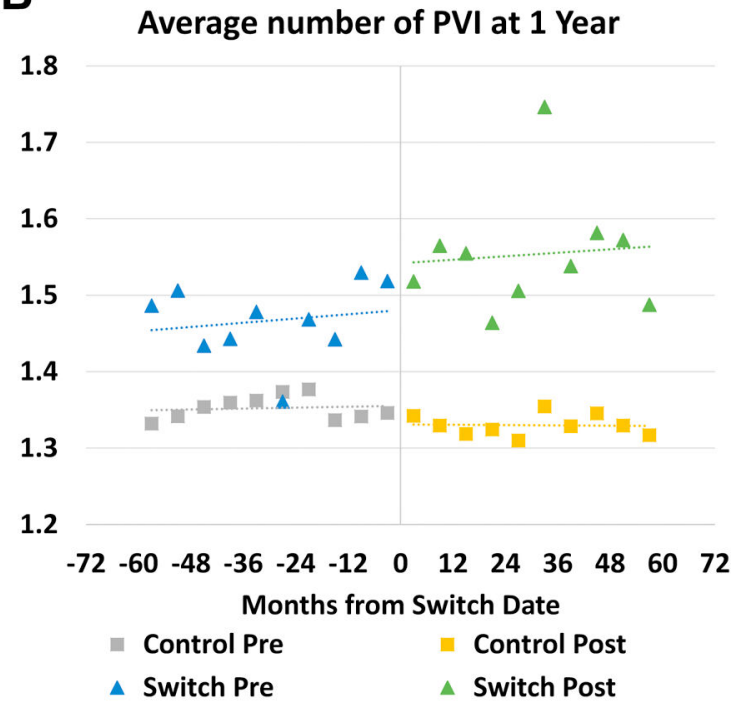

D Percentage of Patients with Repeat PVI at 1- year

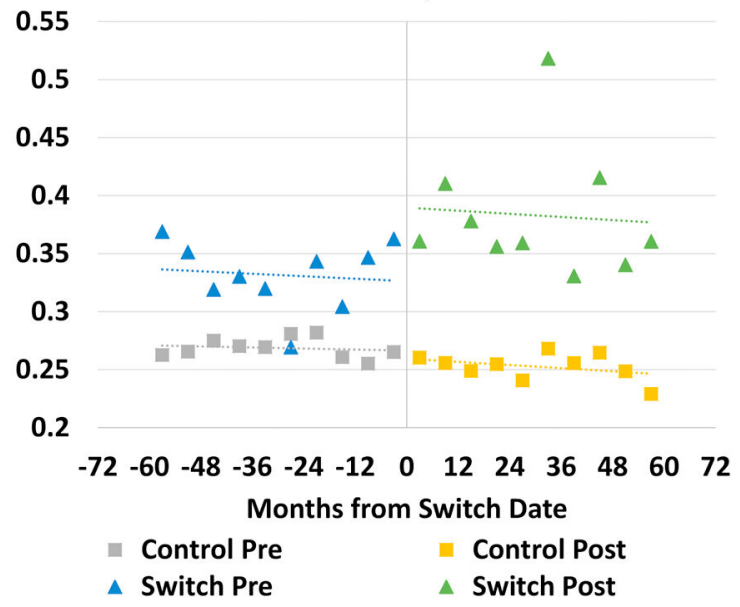

Difference-in-difference model comparing average A) 30-day and B) 1-year PVI rates for switch and control physicians.

Difference-in-difference model comparing repeat PVI at C) 30-days and D) 1-year for switch and control physicians. 
A
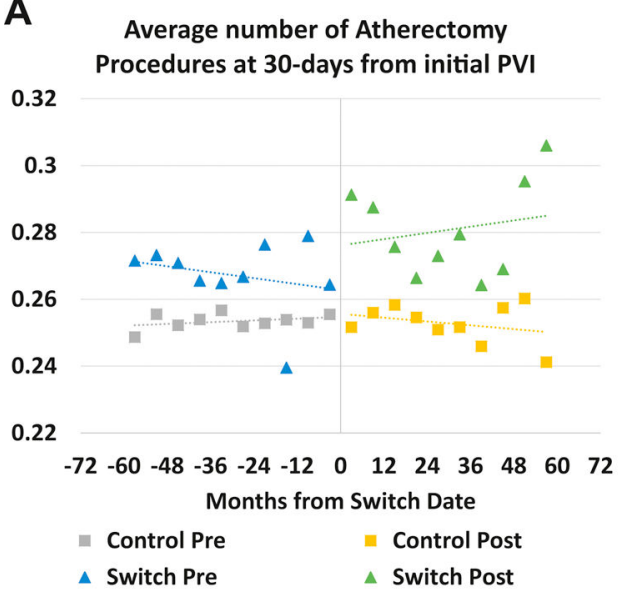

B

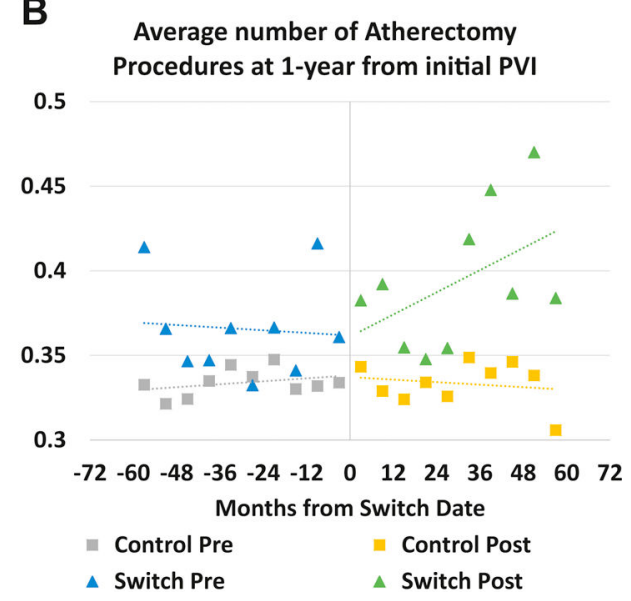

Figure 2.

Difference-in-difference model comparing switch and control physicians use of atherectomy at A) 30-days and B) 1-year. 
Table I.

Physician specialty and location of the first peripherl vascular intervention

\begin{tabular}{|c|c|c|c|c|c|}
\hline Variable & \multicolumn{2}{|c|}{$\begin{array}{l}\text { Switch physicians, } \\
\text { No. }(\%)(\mathrm{n}=292) \\
\end{array}$} & \multicolumn{2}{|c|}{$\begin{array}{l}\text { Control physicians, } \\
\text { No. }(\%)(\mathbf{n}=3715)\end{array}$} & $P$ value \\
\hline Specialty & & & & & $<.001$ \\
\hline General surgery & \multicolumn{2}{|c|}{$47(16.1)$} & \multicolumn{2}{|c|}{$406(10.9)$} & \\
\hline Cardiology & \multicolumn{2}{|c|}{$91(31.2)$} & \multicolumn{2}{|c|}{$1433(38.6)$} & \\
\hline Radiology & \multicolumn{2}{|c|}{$31(10.7)$} & \multicolumn{2}{|c|}{$593(16.0)$} & \\
\hline Vascular surgery & \multicolumn{2}{|c|}{$104(35.6)$} & \multicolumn{2}{|c|}{$941(25.3)$} & \\
\hline Cardiothoracic surgery & \multicolumn{2}{|c|}{$6(2.0)$} & \multicolumn{2}{|c|}{$190(5.1)$} & \\
\hline \multirow[t]{2}{*}{ Other } & \multicolumn{2}{|c|}{$13(4.5)$} & \multicolumn{2}{|c|}{$152(4.1)$} & \\
\hline & \multicolumn{2}{|c|}{ Patients $(n=7134)$} & \multicolumn{2}{|c|}{ Patients $(n=54,213)$} & \\
\hline Location of first procedures & & & & & $<.001$ \\
\hline Inpatient & \multicolumn{2}{|c|}{$2135(29.9)$} & \multicolumn{2}{|c|}{$23,617(43.7)$} & \\
\hline Outpatient (hospital associated) & \multicolumn{2}{|c|}{$2684(37.7)$} & \multicolumn{2}{|c|}{$30,347(56.0)$} & \\
\hline OBL & \multicolumn{2}{|c|}{$2271(31.8)$} & \multicolumn{2}{|c|}{$0(0)$} & \\
\hline \multirow[t]{3}{*}{ Other } & \multicolumn{2}{|c|}{44 (0.6) } & \multicolumn{2}{|c|}{$195(0.4)$} & \\
\hline & \multicolumn{4}{|c|}{ Patients } & \\
\hline & $\begin{array}{c}\text { Preswitch } \\
(\mathbf{n}=3888), \\
\text { No. }(\%)\end{array}$ & $\begin{array}{c}\text { Postswitch } \\
(\mathbf{n}=3246), \\
\text { No. }(\%)\end{array}$ & $\begin{array}{c}\text { Preperiod } \\
(\mathbf{n}=\mathbf{3 6 , 3 2 7}) \\
\text { No. }(\%)\end{array}$ & $\begin{array}{c}\text { Postperiod } \\
(\mathbf{n}=17,886), \\
\text { No. }(\%)\end{array}$ & \\
\hline Location of first procedures & & & & & $<.001 /<.001^{a}$ \\
\hline Inpatient & $1636(42.1)$ & 499 (15.4) & $16,945(46.6)$ & $6726(37.6)$ & \\
\hline Outpatient (hospital associated) & $2123(56.9)$ & $471(14.5)$ & $19,252(53.0)$ & $11,095(62.0)$ & \\
\hline OBL & $0(0)$ & $2271(70.0)$ & $0(0)$ & $0(0)$ & \\
\hline Other & $39(1.0)$ & $5(0.2)$ & $130(0.4)$ & $65(0.4)$ & \\
\hline
\end{tabular}

$O B L$, Office-based laboratory.

${ }^{a}$ Comparison between preswitch vs postswitch / comparison between preperiod vs postperiod. 
Table II.

Patient demographics by stratified by switch periods

\begin{tabular}{|c|c|c|c|c|c|}
\hline \multirow[b]{2}{*}{ Characteristics ${ }^{a}$} & \multicolumn{2}{|c|}{ Switch physicians } & \multicolumn{2}{|c|}{ Control physicians } & \multirow[b]{2}{*}{$P$ value $b$} \\
\hline & $\begin{array}{l}\text { Preswitch } \\
(\mathrm{n}=3888)\end{array}$ & $\begin{array}{l}\text { Postswitch } \\
(\mathrm{n}=3246)\end{array}$ & $\begin{array}{c}\text { Preperiod } \\
(\mathbf{n}=\mathbf{3 6}, \mathbf{3 2 7})\end{array}$ & $\begin{array}{l}\text { Postperiod } \\
(\mathrm{n}=\mathbf{1 7 , 8 8 6})\end{array}$ & \\
\hline Age, years & $75.2 \pm 9.6$ & $75.6 \pm 9.8$ & $74.9 \pm 9.4$ & $75.1 \pm 9.8$ & $.12 / .06 / .44$ \\
\hline Female sex & $1931(49.7)$ & $1570(48.4)$ & $17,810(49.0)$ & $8363(46.8)$ & $.27 /<.001 / .44$ \\
\hline Charlson Comorbidity Index & $5.6 \pm 3.2$ & $6.7 \pm 3.5$ & $5.4 \pm 3.1$ & $6.5 \pm 3.4$ & $<.001 /<.001 / .77$ \\
\hline \multicolumn{6}{|l|}{ Charlson comorbidities } \\
\hline Myocardial infarction & $868(22.3)$ & $934(28.8)$ & $8329(22.9)$ & $5522(30.9)$ & $<.001 /<.001 / .26$ \\
\hline Congestive heart failure & $1681(43.2)$ & $1624(50.0)$ & $15,258(42.0)$ & 8716 (48.7) & $<.001 /<.001 / .98$ \\
\hline Peripheral vascular disease & $3897(99.8)$ & 3244 (99.9) & $36,720(99.8)$ & $17,871(99.9)$ & $.07 / .028 / .40$ \\
\hline Cerebrovascular disease & $2165(55.7)$ & $2240(69.0)$ & $19,466(54.6)$ & $11,485(64.2)$ & $<.001 /<.001 / .01$ \\
\hline Dementia & $322(8.3)$ & $316(9.7)$ & $2171(6.0)$ & $1473(8.2)$ & $.03 /<.001 / .06$ \\
\hline Chronic pulmonary disease & $1823(46.9)$ & $1971(60.7)$ & $17,545(49.3)$ & $10,748(60.1)$ & $<.001 /<.001 / .11$ \\
\hline Rheumatologic disease & $285(7.3)$ & $404(12.5)$ & $2800(7.7)$ & $2009(11.2)$ & $<.001 /<.001 / .05$ \\
\hline Peptic ulcer disease & $243(6.2)$ & $326(10.0)$ & $2239(6.2)$ & $1663(9.3)$ & $<.001 /<.001 / .46$ \\
\hline Mild liver disease & $378(9.7)$ & $493(15.2)$ & $3330(9.2)$ & $2695(15.1)$ & $<.001 /<.001 / .48$ \\
\hline Diabetes & $2245(57.7)$ & $2038(62.8)$ & $19,770(54.5)$ & $10,856(60.7)$ & $<.001 /<.001 / .38$ \\
\hline With chronic complications & $1462(37.6)$ & $1336(41.2)$ & $12,085(33.3)$ & $7003(39.2)$ & $.002 /<.001 / .04$ \\
\hline Hemiplegia or paraplegia & $160(4.1)$ & $200(6.2)$ & $1431(3.9)$ & $1064(5.9)$ & $<.001 /<.001 / .94$ \\
\hline Renal disease & $1295(33.3)$ & $1328(40.9)$ & $12,000(33.0)$ & $7013(39.2)$ & $<.001 /<.001 / .27$ \\
\hline Any malignancy & $675(17.4)$ & $826(25.5)$ & $6352(17.5)$ & $4393(24.6)$ & $<.001 /<.001 / .37$ \\
\hline Moderate or severe liver disease & $32(0.8)$ & $48(1.5)$ & $255(0.7)$ & $250(1.4)$ & $.009 /<.001 / .68$ \\
\hline Metastatic solid tumor & $100(2.6)$ & $105(3.2)$ & $801(2.2)$ & $589(3.3)$ & $.09 /<.001 / .25$ \\
\hline AIDS & $8(0.2)$ & $22(0.7)$ & $107(0.3)$ & $88(0.5)$ & $<.001 /<.001 / .12$ \\
\hline Race/ethnicity & & & & & $.002 / .14 / .37$ \\
\hline Unknown & $2(<0.2)$ & $5(<0.2)$ & $40(<0.2)$ & $27(<0.2)$ & \\
\hline White & $3188(80.8)$ & $2535(84.7)$ & $30,821(84.8)$ & $15,113(84.5)$ & \\
\hline Black & $512(13.2)$ & $541(16.7)$ & 4107 (11.3) & $2018(11.3)$ & \\
\hline Other & $45(1.2)$ & $39(1.2)$ & $266(0.7)$ & $149(0.8)$ & \\
\hline Asian & $29(0.8)$ & $30(0.9)$ & $194(0.5)$ & $123(0.7)$ & \\
\hline Hispanic & $107(2.8)$ & $91(2.8)$ & $656(1.8)$ & $320(1.8)$ & \\
\hline North American Native & $5(<0.2)$ & $5(<0.2)$ & $243(0.7)$ & $136(0.8)$ & \\
\hline \multicolumn{6}{|l|}{ Indication for intervention } \\
\hline PAD + wound & $1341(34.5)$ & $1141(35.2)$ & $11,628(32.0)$ & $6763(37.8)$ & $56 /<.001 /<.001$ \\
\hline
\end{tabular}

$A I D S$, Acquired immunodeficiency syndrome; $P A D$, peripheral artery disease.

${ }^{a}$ Continuous data are presented as the mean \pm standard deviation and categorical data as number (\%).

${ }^{b}$ Comparison between preswitch vs postswitch / comparison between preperiod vs postperiod / difference-in-differences.

J Vasc Surg. Author manuscript; available in PMC 2021 October 29. 
Table III.

Patient outcomes by switch and control physicians

\begin{tabular}{|c|c|c|c|c|c|}
\hline \multirow[b]{2}{*}{ Outcomes $^{a}$} & \multicolumn{2}{|c|}{ Switch physicians } & \multicolumn{2}{|c|}{ Control physicians } & \multirow[b]{2}{*}{$P$ value $b$} \\
\hline & $\begin{array}{l}\text { Preswitch } \\
(\mathbf{n}=3888)\end{array}$ & $\begin{array}{c}\text { Postswitch } \\
(\mathrm{n}=3246)\end{array}$ & $\begin{array}{c}\text { Preperiod } \\
(\mathbf{n}=\mathbf{3 6 , 3 2 7})\end{array}$ & $\begin{array}{l}\text { Postperiod }{ }^{d} \\
(\mathrm{n}=17,886)\end{array}$ & \\
\hline \multicolumn{6}{|c|}{ Average PVIs per patient, No. } \\
\hline 30 days & $1.10 \pm 0.31$ & $1.16 \pm 0.38^{e}$ & $1.09 \pm 0.31$ & $1.09 \pm 0.31^{f}$ & $<.001$ \\
\hline 1 year & $1.39 \pm 0.73$ & $1.49 \pm 0.81^{e}$ & $1.33 \pm 0.67$ & $1.31 \pm 0.64^{e}$ & $<.001$ \\
\hline \multicolumn{6}{|c|}{ Patients with secondary PVI } \\
\hline 30 days & $380(9.8)$ & $489(15.1)^{e}$ & $3234(8.9)$ & $1595(8.9)^{f}$ & $<.001$ \\
\hline 1 year & $1129(29.0)$ & $1146(35.3)^{e}$ & $9189(25.3)$ & $4317(24.1)^{g}$ & $<.001$ \\
\hline \multicolumn{6}{|c|}{ Type of first intervention } \\
\hline Balloon & $898(23.1)$ & $781(24.1)^{f}$ & $8434(23.2)$ & $3671(20.5)^{e}$ & $<.001$ \\
\hline Stent & $2065(53.1)$ & $1607(49.5)^{g}$ & $20,484(56.4)$ & $9530(53.3)^{e}$ & .27 \\
\hline Atherectomy & $925(23.8)$ & $858(26.4)^{h}$ & 7409 (20.4) & $4685(26.2)^{e}$ & .005 \\
\hline \multicolumn{6}{|c|}{ Average atherectomies per patient, No. } \\
\hline 30 days & $0.27 \pm 0.49$ & $0.32 \pm 0.53^{e}$ & $0.23 \pm 0.46$ & $0.29 \pm 0.50^{e}$ & .002 \\
\hline 1 year & $0.36 \pm 0.66$ & $0.43 \pm 0.72^{g}$ & $0.30 \pm 0.60$ & $0.37 \pm 0.62^{g}$ & .008 \\
\hline \multicolumn{6}{|l|}{ MALEs } \\
\hline 30 days & $221(5.7)$ & $168(5.2)^{f}$ & $2075(5.7)$ & $920(5.1)^{g}$ & .87 \\
\hline 1 year & $606(15.6)$ & $409(12.6)^{e}$ & $5351(14.7)$ & $2253(12.6)^{e}$ & .20 \\
\hline \multicolumn{6}{|c|}{ Above-ankle amputation } \\
\hline 30 days & $88(2.3)$ & $37(1.1)^{e}$ & $826(2.3)$ & $368(2.1)^{f}$ & .009 \\
\hline 1 year & $291(7.5)$ & $155(4.8)^{e}$ & $2444(6.7)$ & $1021(5.7)^{e}$ & 0.02 \\
\hline \multicolumn{6}{|l|}{ Hospitalization } \\
\hline 30 days & $946(24.3)$ & $573(17.6)^{e}$ & $8641(23.8)$ & $4181(23.4)^{f}$ & $<.001$ \\
\hline 1 year & $2383(61.3)$ & $1565(48.2)^{e}$ & $21,421(59.0)$ & $9334(52.2)^{e}$ & $<.001$ \\
\hline \multicolumn{6}{|l|}{ Death } \\
\hline 30 days & $40(1.0)$ & $10(0.3)^{e}$ & $392(1.1)$ & $87(0.5)^{e}$ & .41 \\
\hline 1 year & $269(6.9)$ & $83(2.6)^{e}$ & $2228(6.1)$ & $453(2.5)^{e}$ & .81 \\
\hline
\end{tabular}

MALEs, Major adverse limb events (open revascularization, thrombectomy, above-ankle amputation, or a combination of these); $P V I$, peripheral vascular intervention.

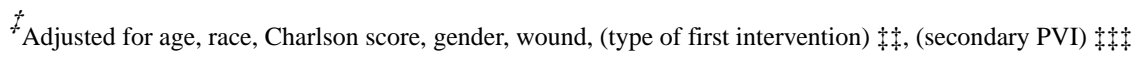

${ }^{a}$ Continuous data are presented as mean 6 standard deviation and categorical data as number $(\%)$.

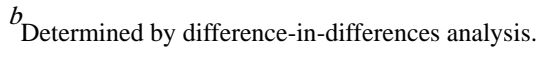

${ }^{c}$ Comparison between preswitch vs postswitch.

J Vasc Surg. Author manuscript; available in PMC 2021 October 29. 
${ }^{d}$ Comparison between preperiod vs postperiod.

$e_{P<.001 .}$.

$f_{P \geq .05}$ (not significant).

$g_{P<.01 .}$

$h_{P<.05}$. 